\title{
REFLEXÕES DE ESTUDANTES EM EDUCAÇÃO FÍSICA ACERCA EXPERIÊNCIAS VIVENCIADAS NO PIBID
}

\author{
BERTI, Luiz Henrique ${ }^{1}$ \\ BERTI, Mirelli Montegutti ${ }^{2}$ \\ FRASSON, Jéssica ${ }^{3}$ \\ PEREIRA, Viviane Ribeiro ${ }^{4}$ \\ PEREIRA, Taina ${ }^{5}$ \\ SILVEIRA, Vanessa da Silva da ${ }^{6}$
}

\section{INTRODUÇÃO}

Esse estudo se propõe a compreender de que forma a reflexão da práxis pode contribuir para umamelhora na aula e na formação docente, sendo estes uns dos objetivos do PIBID, proporcionar a Iniciação Docente.

Esse objetivo instigou a busca de respostas para o seguinte problema de pesquisa: Qual a importância da reflexão crítica da práxis pedagógica para a organização da atividade de ensino?

A Educação Física é alvo de debates antigos acerca da sua essência, em que pesquisas de diferentes épocas apontam as discussões sobre as divisões de mente/corpo. Segundo Euzébio; Ortigara (2011), há uma superação dessa visão dicotômica da área, o que busca legitimar sua importância dentro do âmbito escolar. Essa legitimação da Educação Física enquanto área de conhecimento pode ser compreendida através das propostas pedagógicas que possibilitam aos professores oportunidade de dialogar e participar da construção de estudantes críticos e reflexivos. Para isso, nos embasamosna proposta Critico Superadora, discutida pelo Coletivo de Autores (1992).

\footnotetext{
${ }^{1}$ Universidade do Extremo Sul Catarinense (UNESC); henriqueberti@outlook.com

${ }^{2}$ Universidade do Extremo Sul Catarinense (UNESC); mimi_bianco@hotmail.com

${ }^{3}$ Universidade Federal do Rio Grande do Sul (UFRGS); jehfrasson@hotmail.com

${ }^{4}$ Universidade do Extremo Sul Catarinense (UNESC); vivianeribeirop@hotmail.com

${ }^{5}$ Universidade do Extremo Sul Catarinense (UNESC); tainapereira003@hotmail.com

${ }^{6}$ Universidade do Extremo Sul Catarinense (UNESC); vanessa.renan_@hotmail.com
} 


\section{METODOLOGIA}

As aulas que foram ministradas no PIBID foram elaboradas de acordo com a proposta pedagógica Critico Superadora. A proposta é base de discussão no subprojeto do PIBID de Educação Física, e também na formação acadêmica do curso de Educação Física - licenciatura da graduação em uma Universidade do Extremo Sul Catarinense.

O nível de ensino de atuação do PIBID foios anos finais do Ensino Fundamental. Deste modo,Coletivo de Autores (1992) em sua sugestãodo ensino por ciclo, situa-ono terceiro ciclo, que trata da $7^{\underline{a}}$ e $8^{\underline{a}}$ série ( $8^{\circ}$ e $9^{\circ}$ ano atuais). Neste ciclo se realiza a ampliação da sistematização do conhecimento.

\footnotetext{
O aluno amplia as referências conceituais do seu pensamento; ele toma consciência da atividade teórica, ou seja, de que uma operação mental exige a reconstituição dessa mesma operação na sua imaginação para atingir a expressão discursiva, leitura teórica da realidade (COLETIVO DE AUTORES, 1992, p. 35).
}

Levando em consideração a organização do conhecimento por ciclos, tentamos organizar e sistematizar oensino de acordo com a propostaCritico Superadora.

O conteúdo abordado nas aulas ministradas foi os diferentes tipos de futebóis, em que se tinha como objetivo desmistificar o futebol de campo hegemonicamente conhecido pelos educandos, para que pudessem vivenciar outraspossibilidades de futebóis já organizadas socialmente, porém pouco utilizadas no espaço escolar.

Para tal objetivo foram apresentados aos alunos o rugby, o futebol digital e virtual, o futebol paraolímpico e o futebol americano.

No decorrer das atuações foram realizados estudos, pesquisas, e promovidas discussões entre os bolsistas, professor supervisor e nos encontros presenciais do subprojeto, possibilitado a ampliação do conhecimento sobre a prática docente e a vivência escolar.

Vale ressaltar que foi possível perceber estas questões direcionando o olhar, pois é importante ter pontos de observação pré-estabelecidos, para obter 
uma observação melhor da situação, devendo ter somente um foco por vez, para que não ocorra confusões (WEFFORT, 1995).

\section{REFLEXÃO DA PRÁTICA DOCENTE EMBASADA EM UMA CONCEPÇÃO CRÍTICA DA EDUCAÇÃO FíSICA}

A partir das atuações na escola, os acadêmicos e professor supervisor conversavam e discutiam sobre a atuação do acadêmico que havia lecionado naquele dia. Estes debates foram o percursor de todo o debate deste artigo, pois foi a partir destes que os acadêmicos começaram a se perceber como sujeitos em processo de formação constantemente. Isso porque, ambas as experiências eram postas em diálogo, ou seja, o professor supervisor que já possui muitos anos de experiências fazia críticas construtivas sobre a aula ministrada pelo acadêmico.

Mas, os acadêmicos também realizavam críticas construtivasembasadas na proposta CríticoSuperadora, pois como o professor supervisor não tem conhecimento sobre tal proposta, os acadêmicos faziam este intermédio. Vale ressaltar para este ponto, que foi de grande aprendizagem ao professor supervisor da escola, uma vez que contribuiu para sua formação e arcabouço de conhecimentos.

A partir destas conversas e discussões foi possível perceber como a reflexão da prática se faz necessária no percurso docente dos professores. Neste sentido,Coletivo de Autores (1992, p. 28) aponta que, "[...] uma reflexão pedagógica ampliada e comprometida com os interesses das camadas populares tem como eixo a constatação, a interpretação, a compreensão e a explicação da realidade social complexa e contraditória".

Freire (2011)apresenta a reflexão de que para os futuros professores saírem do pensamento ingênuo para o pensar certo, é necessário que os mesmos produzam juntamente com seus professores formadores, este saber certo, sempre numa construção com o professor formador. Neste sentido, Freire (2011, p.40) apresenta que é preciso "[...] possibilitar, que, voltando-se sobre si mesma, através 
da reflexão sobre a prática, a curiosidade ingênua, percebendo-se como tal, se vá tornando crítica".

É necessário que o professor se compreenda como um ser inacabado para assim cada vez mais fazer do seu saber ingênuo um saber certo, por meio da curiosidade epistemológica.

Gosto de ser gente porque, inacabado, sei que sou um ser condicionado, mas, consciente do inacabamento, sei que posso ir mais além dele. Esta é a diferença profunda entre o ser condicionado e o ser determinado. A diferença entre $o$ inacabado que não se sabe como tal e o inacabado que histórica e socialmente alcançou a possibilidade de saber-se inacabado(FREIRE, 2011, p.52-53).

Segundo Freire (2011) é imprescindível que a teoria se aproxime sempre da prática, para que o meu testemunho não acabe perdendo a veracidade, caso contrário,"[...] me torno tão falso quanto quem pretende estimular o clima democrático na escola por meios e caminhos autoritários" (FREIRE, 2011, p.48). Deste modo, procuramos realizar nossa prática pedagógica sempre o mais próximo possível da teoria.

Aperspectivado Coletivo de Autores (1992) traz algumas propostas de como trabalhar os conteúdos da Educação Física na escola, em que o mesmo define por Cultura Corporal. Propõe uma Educação Física com um olhar crítico para as questões sociais, tendo como seu foco principal a superação de classes. A perspectiva aponta a reflexão pedagógica como necessária trazendo a caracterização diagnóstica, judicativa e teleológica, e alguns pontos essenciais para um currículo ampliado.

Neste sentido, Coletivo de Autores (1992) traz alguns princípios para sistematização e organização dos conteúdos, para que haja uma maior organicidade dos mesmos e por vezes uma melhor compreensão dos alunos.

Sendo oConfronto e Contraposição dos Saberes, o que se refere ao saber que o educando aprende em ambientes informais, que não devem ser desconsiderados, assim ele estará confrontando com o saber científico adquirido na escola, fazendo uma reflexão pedagógica fundamental para seu pensamento crítico e autônomo. 
Já a Simultaneidade dos Conteúdos,traz enquanto dados da realidade e espiralidade da incorporação das referências do pensamento, pois nas escolas, como é possível visualizar claramente nos livros didáticos, os conteúdos são fragmentados e isolados por unidades. Mediante a isso dificultando a visão de totalidade do educando, ou seja, limitando-o.

A Espiralidadeem que o conhecimento do educando não deve se dar de forma linear e sim de forma "espiral", ou seja, ampliando seu conhecimento a cada conteúdo adquirido, assim fazendo reflexões pedagógicas.

E por fim, a Provisoriedade do Conhecimento como último princípio aqui tratado,em que o professor deve deixar explícito para o educando os conteúdos que serão trabalhados. Logo, o professor deve explicar que somos todos seres históricos, e que o que temos hoje é fruto de construções de sociedades passadas, que a cada dia se aperfeiçoam mais. Fazendo com que 0 aluno perceba que é construtor da história, e que é capaz de modificar a realidade.

\section{REFLEXÃO DAS PRÁXIS}

Desta forma, perante esta breve explanação da proposta Critico Superadora, abaixo será descrito a organização da atuação na instituição escolar e algumas reflexões sobre a mesma.

O professor supervisor do PIBID possuía em seu planejamento anual como um dos conteúdos o futebol de campo, o qual tivemos a oportunidade de acompanhar. Outro elemento observado é que o conteúdo escolhido pelo professor estava presente cotidianamente na realidade dos estudantes.

Desta forma, podemos observar que a relevância social também foi um dos princípios essenciais para a seleção do conteúdo, que implica na compreensão do sentido e o significado do conteúdo para comunidade escolar, em especial aos alunos. Por isso acreditamos que a partir da situação observada, da presença do futebol de campo já muito pertinente no cotidiano dos alunos, se fez relevante trazer novas formas de jogar futebol e novas culturas (COLETIVO DE AUTORES, 1992).

Para uma maior compreensão do conteúdo por parte dos alunos, foram adequadas às aulas, as possibilidades sociocognocitivas, em que é o último 
princípio para seleção do conteúdo. "Há de se ter, no momento da seleção, competência para adequar o conteúdo à capacidade cognitiva e à prática social do aluno, ao seu próprio conhecimento e às suas possibilidades enquanto sujeito histórico" (COLETIVO DE AUTORES, 1992, p.31).

A organização e divisão das aulas de atuação dos diferentes futebóis,foram debatidosno grupo de atuação na escola, juntamente com professor supervisor da escola, para que assim chegássemos num consenso todos juntos. Neste sentido, ficou definido que cada tema seria desenvolvido por duplas, ou seja, cada dupla ficaria com um dos tipos de futebóis.

A dupla consistia em um bolsista da quarta-feira e um de sexta-feira, para que assim possibilitasse a continuidade no tema abordado. Ficaram definido seis aulas para cada tema, pois Coletivo de Autores (1992) traz como um número mínimo de três a quatro aulas para trabalhar minimamente a Cultura Corporal na escola, nesse sentido ampliamos o número de aula para podermos ter um melhor processo de ensino-aprendizagem.

Os temas abordados seguiram a seguinte sequencia: Rugby, futebol virtual, futebol paraolímpico e futebol americano. "[...] entendemos a aula como um espaço intencionalmente organizado para possibilitar a direção da apreensão, pelo aluno, do conhecimento especifico da Educação Física e dos diversos aspectos das suas práticas na realidade social” (COLETIVO DE AUTORES, 1992, p.87).

Durante o período que os acadêmicos atuaram, foram realizadas conversas entre os acadêmicos e o professor após o término das aulas e nos horários de planejamento que o professor se dispôs. Ocorriam às devidas conversar para que professor supervisor e bolsistas pudessem discutiam pontos relevantes sobre a atuação feita anteriormente por um dos acadêmicos que estava atuando. Mediante disso, sendo possível uma reflexão crítica do grupo sobre os pontos positivos e os que poderiam ser alterados em próximas práticas.

Tardif (2002) traz que os professores são considerados reflexivos e que, produzem saberes específicos ao seu trabalho, onde são capazes de partilhá-las, aperfeiçoá-las e de inova-las, aumentando assim sua eficácia.

Ressalta-se que as aulas que aconteciam nas quartas-feiras eram com quatrobolsista de nas sextas-feiras com mais quatro bolsistas distintos. Um fato que dificultou as reflexões do grupo de quarta-feira, foi o professor não ter horários 
de hora atividade disponível, prejudicando assim a reflexão da prática, diferente das aulas de sexta-feira que possui um tempo disponível para a mesma. Sendo que, para ser realizada esta conversa com tais bolsistas de quarta-feira, ficou definido que as mesmas seriam após o término das aulas.

Perin (2009) acredita que na formação inicial o professor iniciante deve ter o acompanhamento necessário para seu processo de desenvolvimento, onde destacamos como o cortejo do professor supervisor e outros acadêmicos do projeto PIBID são de extrema importância, pois assim a evolução do professor iniciante é mais ampla e rica, no sentido troca de experiências.

Nas discussões sobre a prática, foram levantados alguns pontos de extrema importância como, por exemplo, a melhora na retomada das aulas anteriores para que os alunos pudessem estar retomando as aulas anteriores, fazendo assim a relação com a prática do dia a ser lecionado com as práticas passadas, assim como também foi discutido para que si fizesse um fechamento da aula de forma mais ampla, para que os alunos e o professor pudessem visualizar qual foi a compreensão da turma diante do conteúdo ministrado.

Para uma maior organização dos slides, da conduta com a turma ou domínio da mesma e melhoria na prática das atividades, foram traçadas algumas metodologias diferentes, durante o período de atuação dos acadêmicos. Essas mudanças das metodologias surgiram a partir das experiências dos outros bolsistas, e de questões que acreditávamos ser necessária modificar. Sendo assim, Tardif (2002, p.53-54)alega sobre a importância da experiência, em que
A experiência provoca,assim, um efeito de retomada crítica(retroalimentação)dos saberes adquiridos antes ou fora da prática profissional. Ela filtra e seleciona os outros saberes, permitindo assim aos professores reverem seus saberes, julgá-los e avaliá-los e, portanto, objetivar um saber formado de todos os saberes retraduzidos e submetidos ao processo de validação constituído pela prática cotidiana.

A partir de conversas entre as duplas ficou definido que seria realizado um questionário inicial para fazer um diagnóstico da turma, ou seja, dos conhecimentos que eles já apresentavam, partindo da sua experiência de vida. Após o término do conteúdo seria realizado um questionário novamente para fazer uma avaliação do conhecimento que foi internalizado pelos mesmos. 
Perante as discussões sobre a aplicação dos questionários nas aulas, surgiu à necessidade de trocarmos a metodologia, pois a partir das reações dos alunos foi possível perceber uma falta de estímulo. Sendo assim as duplas seguintes trocaram a sua forma avaliar, fazendo assim uma conversa inicial a cada tema novo para fazer um diagnóstico do conteúdo que seria abordado, já para fazer uma avaliação final da compreensão do tema dos alunos, foram realizados um quiz e uma prova objetiva.

Para compreender a questão da avaliação, portanto, não se pode cair no reducionismo de um universo meramente técnico de entendimento, sendo necessária a consideração de outras dimensões desse processo como, por exemplo, as suas significações, implicações e consequências pedagógicas, politicas e sociais(COLETIVO DE AUTORES, 1992, p. 103).

Nesse sentido, percebe-se que foi modificado metodologias e conceitos sobre a prática pedagógica assim intensificando ainda mais nosso conhecimento sobre o ambiente escolar.

\section{CONCLUSÕES}

Por meio das atuações percebemos o quão importante foi as conversas e discussões para a reflexão da nossa práxis docente. Neste sentido, acreditamos que cada vez mais se faça necessário trazer questões como está para o meio acadêmico, para que o professor se perceba como um ser inacabado, que deve sempre estar revendo sua prática docente, por meio de estudos e discussões.

Perante esta análise de conjuntura, acreditamos que foi importante trazer diferentes formas de futebóis, sendo eles o rúgbi, futebol americano, futebol paraolímpico e futebol virtual e digital, pelo fato de ser contemporâneo. O professor deve apresentar o conhecimento que há de mais moderno para as suas aulas, sendo que estes podem ser atuais ou clássicos (COLETIVO DE AUTORES, 1992).

Após todas as discussões, debates e pesquisas, acreditamos ser necessário areflexão da prática pedagógica, pois ela é um dos meios para que o professor(a) tenha respostas do porquê suas aulas não vem acontecendo conforme o esperado. Atuamos em uma proposta crítica da Educação Física, logo temos a clareza de seu aspecto teórico. É no processo de efetivação da prática, que 
sabemos se estamos ministrando as aulas conforme a proposta, dessa forma, isso se da através de uma reflexão crítica de todo o processo (PERIN, 2009).

Percebemos também que as trocas de experiências por meio de diálogos e reflexões sobre as atuações, nos possibilitou um maior conhecimento sobre a prática docente e a vivência escolar.Foi possível identificar que o número de seis aulas para ministrar um conteúdo, é extremamente pequeno para que se possa fazer um aprofundamento do conhecimento sobre o conteúdo e da própria imersão na cultura escolar.

Cancherini (2009) traz por meio de seus estudos que, havendo a necessidade de encontrar respostas, para a prática que não teve grande sucesso, professores colocam justificativas sobre a ineficiência, ao invés de realizar uma reflexão crítica sobre sua prática docente, onde muitas vezes as dificuldades encontradas na realidade das escolas. D

essa forma, o professor iniciante ao vivenciar os desafios do dia-dia da escola e dentro da sala de aula, percebendo os obstáculos, que interferem diretamente em suas aulas, contribuindo para a ideia de "o que fazer com os alunos", havendo a dificuldade de colocar a teoria vista em sua formação acadêmica na prática escolar,em que o mesmo começa a agir de acordo com o movimento da realidade encontrada na escola, ou seja, a acomodação, conceituando a teoria aprendida na instituição formadora como ineficaz na escola. (CANCHERINI, 2009).

No entanto, o professor precisa estar atento em relação com a administração da escola e com os outros professores, devendo assim haver uma socialização entre os sujeitos do âmbito escolar, contribuindo para que possa realizar uma melhor reflexão sobre sua prática dentro da sala de aula (CANCHERINI, 2009).

\section{REFERÊNCIAS}

CANCHERINI, Angela. A socialização do professor iniciante: um difícil começo. 212 f. dissertação (mestrado) - Programa de pós-graduação em educação, PUC, Santos, 2009. 
COLETIVO DE AUTORES. Metodologia do Ensino da Educação Física. Cortez. São Paulo, 1992.

EUZÉBIO, Carlos A.; ORTIGARA, Vidalcir. Na Teoria a Prática é Outra? Análise do Conhecimento Esporte Nos Cursos De Formação Inicial De Professores De Educação Física No Sul Catarinense. Rev. Bras. Ciênc. Esporte, Florianópolis, v. 33, n. 3, p. 653-669, jul./set. 2011.

FREIRE, Paulo. Pedagogia da autonomia: saberes necessários à prática educativa. Paz e Terra. São Paulo, 2011.

PERIN, Andréa Pavan. Dificuldades vivenciadas por professores de matemática em início de carreira. 142 f. Dissertação (Mestrado) - Programa de Pós-Graduação em Educação, UNIMEP, Piracicaba, 2009.

TARDIF, Maurice. Saberes docentes e formação profissional. Petrópolis: Vozes, 2005.

WEFFORT, Madalena F. Educando o olhar da observação. In WEFFORT, Madalena F. (Org.).Observação, registro, reflexão: Instrumentos metodológicos I. São Paulo: Espaço Pedagógico, 1995. 